\title{
PRODUKTIVITAS PEKERJA DI TIGA PROVINSI JAWA DAN BALI
}

\author{
( Worker Productivity in Three Provinces of Java and Ball)
}

\author{
Mukti Ratna Dewi ${ }^{\mathbf{1}}$, Lucia Ari Dinanti ${ }^{\mathbf{1}}$ \\ Departemen Statistika Bisnis, Fakultas Vokasi, Institut Teknologi Sepuluh Nopember ${ }^{1}$ \\ Sukolilo, Surabaya, Jawa Timur \\ E-mail: mukti ratna@its.ac.id
}

\begin{abstract}
ABSTRAK
Menurut Tefi Mathias (2004) produktivitas pekerja di DKI Jakarta mencapai 77.69 juta per orang per tahun pada tahun 2002, sedangkan menurut Purba S., dkk. produktivitas di DKI tahun 2013 mencapai 24.6 juta per orang per tahun. Hal ini menunjukkan terjadinya penurunan produktivitas selama 11 tahun sejak tahun 2002 sampai 2013. Selain itu, berdasarkan hasil Sarkernas tahun 2017 diperoleh bahwa produktivitas pekerja di Bali pada tahun 2017 dinilai rendah yaitu 60.44 juta rupiah per pekerja. Tujuan penelitian ini adalah meneliti pertumbuhan produktivitas pekerja selama enam tahun terakhir di provinsi lain. Dalam hal ini, provinsi yang dipilih adalah Bali, Jawa Timur dan Jawa Tengah karena data PDRB dan jumlah pekerja yang disediakan oleh BPS masing-masing provinsi dinilai paling lengkap dibandingkan provinsi lain. Hasil penelitian menunjukkan bahwa rata-rata produktivitas paling tinggi adalah Provinsi Bali yang mencapai $88 \%$ dalam enam tahun terakhir. Hal ini disebabkan rata-rata pertumbuhan produktivitas dari tahun ke tahun mencapai $9.5 \%$ dan juga karena didukung rata-rata pertumbuhan per sektor yang paling tinggi mencapai $16 \%$ sampai $28 \%$. Sementara itu, Jawa Timur hanya memiliki rata-rata pertumbuhan sektor sebesar $10 \%$.
\end{abstract}

Kata kunci: produktivitas pekerja, ANAVA, PDRB

\section{ABSTRACT}

According to Tefi Mathias (2004), the productivity of workers in DKI Jakarta reached 77.69 million per person per year in 2002, while according to Purba S. et al the productivity in DKI in 2013 reached 24.6 million per person per year. It showed the decline in productivity for 11 years from 2002 to 2013. In addition, based on the results of Sarkernas in 2017 it was found that the productivity of workers in Bali in 2017 was considered low at 60.44 million rupiah per worker. The purpose of this study was to examine the productivity growth of workers over the past six years in other provinces. In this case, the chosen provinces are Bali, East Java, and Central Java because the data of GRDP and the number of workers provided by BPS in each province are considered the most complete compared to other provinces. The results of this study indicated that the highest average productivity was the Province of Bali which reached $88 \%$ in the last six years. This was due to an average productivity growth of $9.5 \%$ from year to year and also supported by the highest average growth per sector reaching $16 \%$ to $28 \%$. Whereas in East Java, the average growth of the sector only reached $10 \%$.

Keywords: worker productivity, ANOVA, GRDP

\section{PENDAHULUAN}

Produktivitas adalah rasio antara output dan input (Heizer \& Render, 2014). Ada tiga macam produktivitas yaitu produktvitas makro, produktivitas mikro, dan produktivitas individu. Produktivitas pekerja di tingkat provinsi merupakan jenis produktivitas regional dan termasuk produktivitas makro. Output dari produktivitas regional adalah Produk Domestik Regional Bruto (PDRB) yang dihasilkan di tingkat provinsi, sementara inputnya merupakan jumlah tenaga kerja yang terserap di wilayah tersebut.

Pulau Jawa terdiri atas enam provinsi yaitu Banten, DKI Jakarta, Jawa Barat, Jawa Tengah, Yogyakarta, dan Jawa Timur. Semua provinsi diresmikan pada tahun yang sama yaitu tahun 1950, kecuali DKI Jakarta dan Banten yang masing-masing diresmikan tahun 1961 dan tahun 2000. Sementara itu, Provinsi Bali diresmikan pada tahun 1958. Dari ketujuh provinsi tersebut, Jawa Timur memiliki wilayah paling luas, yaitu sebesar $47.921 \mathrm{~km}^{2}$.

Tefi Mathias dalam tesisnya menyatakan bahwa produktivitas pekerja di DKI Jakarta mencapai 77.69 juta per orang per tahun pada tahun 2002 (Tefi, 2004). Sementara menurut Purba, dkk. produktivitas di DKI tahun 2013 mencapai 24.6 juta per orang per tahun (Purba, Hasan, Marhaeni, 
\& Rustam, 2016). Hal ini menunjukkan terjadinya penurunan produktivitas sejak tahun 2002 sampai tahun 2013. Selain itu, Purba, dkk. dalam buku Pengukuran Produktivitas Nasional, Regional dan Sektoral Tahun 2016 menyatakan bahwa produktivitas tenaga kerja di Indonesia antara tahun 20112015 terus meningkat di mana pada tahun 2015 mencapai 78.18 juta per orang dari 67.84 juta per orang di tahun 2011. Dengan kata lain, dalam lima tahun terjadi peningkatan produktivitas sekitar $15 \%$ dan rata-rata kenaikan produktivitas sebesar $3.6 \%$ per tahun.

Berdasarkan latar belakang tersebut, muncul pertanyaan mengenai pertumbuhan produktivitas di provinsi lain di Jawa dan Bali. Oleh karena itu, analisis produktivitas dilakukan untuk menyelidiki peningkatan produktivitas pekerja selama kurun waktu 2013 - 2018 di Provinsi Jawa Timur, Jawa Tengah, dan Bali.

\section{METODE}

Untuk mengukur produktivitas di tingkat provinsi diperlukan dua variabel kualitas yaitu PDRB sebagai output dan Jumlah Tenaga Kerja sebagai input. Kedua variabel ini merupakan data sekunder yang diambil dari website BPS masing-masing provinsi. Definisi kedua variabel tersebut adalah sebagai berikut:

1. PDRB merupakan singkatan dari Produk Domestik Regional Bruto, yaitu jumlah nilai tambah barang dan jasa yang dihasilkan dari seluruh kegiatan pekonomian di seluruh daerah dalam tahun tertentu atau periode tertentu (biasanya satu tahun). Pada studi ini digunakan PDRB atas dasar harga konstan yang dihitung dengan menggunakan harga pada tahun tertentu sebagai tahun dasar.

2. Jumlah Tenaga Kerja adalah banyaknya tenaga kerja yang terserap di berbagai sektor di tingkat provinsi.

Sementara produktivitas regional di hitung dengan Persamaan (1).

$$
\text { Produktivitas }=\frac{\text { PDRB }}{\text { Jumlah Tenaga Kerja }}
$$

Metode yang digunakan dalam penelitian ini adalah Analisis Varians (ANAVA) Dua Arah. Metode ini digunakan untuk menyelidiki efek perbedaan level dari dua faktor. Prinsip kerja ANAVA Dua Arah adalah membandingkan rasio varians faktor dan varians galat yang berdistribusi $F(F$ hitung) dengan nilai $F$ tabel yang besarnya tergantung dari tingkat signifikan dan derajat bebas faktor dan derajat bebas galat.

Jika $T_{i}$ adalah efek faktor-1 dan $\beta_{i}$ adalah efek faktor-2 maka hipotesis yang digunakan untuk menguji signifikansi efek perbedaan faktor-1 dan faktor-2 adalah:

1. $H_{0}: T_{1}=T_{2} \ldots \ldots=T_{i}=0$ (tidak ada efek faktor-1 terhadap respon)

$\mathrm{H}_{1}$ : paling sedikit ada satu $\mathrm{T}_{\mathrm{i}} \neq 0$

2. $H_{0}: \beta_{1}=\beta_{2 \ldots \ldots}=\beta_{j}=0$ (tidak ada efek faktor-2 terhadap respon)

$\mathrm{H}_{1}$ : paling sedikit ada satu $\beta_{\mathrm{j}} \neq 0$

Hipotesis di atas diuji dengan statistik uji $F$ pada Tabel. (Montgomery, 2001)

Tabel 1. Struktur Tabel ANAVA Dua Arah.

\begin{tabular}{|c|c|c|c|c|}
\hline Sumber Variasi & $\begin{array}{c}\text { Jumlah } \\
\text { Kuadrat } \\
\text { (JK) }\end{array}$ & $\begin{array}{c}\text { Derajat Bebas } \\
\text { (db) }\end{array}$ & $\begin{array}{l}\text { Rata-rata Jumlah } \\
\text { Kuadrat (RJK) }\end{array}$ & $\begin{array}{l}\text { Fhitung } \\
\left(F_{\mathrm{h}}\right)\end{array}$ \\
\hline Faktor-1 & JKF1 & $a-1$ & $R J K F 1=J K F 1 / a-1$ & $F_{h_{1}}=\mathrm{RJKF} 1 / \mathrm{RJKG}$ \\
\hline Faktor-2 & JKF2 & $b-1$ & $\mathrm{RJKF} 2=\mathrm{JKF} 2 / b-1$ & $F_{h 2}=R J K F 2 / R J K G$ \\
\hline Galat & JKG & $(a-1)(b-1)$ & $\begin{array}{l}\text { RJKG }=J K G /[(a-1)(b- \\
\text { 1)] }\end{array}$ & \\
\hline Total & JKT & $a b-1$ & & \\
\hline
\end{tabular}

$\mathrm{H}_{0}$ ditolak pada tingkat signifikan a jika $F_{\mathrm{h} 1}>F_{\mathrm{a}}(\vartheta 1, \vartheta g)$ dan $F_{\mathrm{h} 2}>F_{\mathrm{a}}(\vartheta 2, \vartheta g)$ dengan $\vartheta 1$ dan $\vartheta 2$ berturut-turut adalah derajat bebas faktor-1 dan faktor-2 dan $\vartheta_{\mathrm{g}}$ adalah derajat bebas galat. Keoutusan tolak $\mathrm{H}_{0}$ juga dapat didasarkan pada $p$-value yang merupakan peluang $F$ hitung lebih dari $F$ tabel pada tingkat signifikan a, $p$-value $=\mathrm{P}\left(F_{\mathrm{h}}>F_{\mathrm{a}} ;(\vartheta 2, \vartheta \mathrm{e})\right) . \mathrm{H}_{0}$ ditolak untuk efek faktor ke- $i$ 
pada level a jika $p$-value faktor ke-i nilainya kurang dari a. Perhitungan JKT, JKG, dan JKP dapat dilakukan dengan formula berikut:

$$
\begin{aligned}
\mathrm{JKT} & =\sum_{i=1}^{a} \sum_{j=1}^{b} y_{i j}^{2}-\frac{y_{. .}^{2}}{N} \ldots \ldots . . . \\
\mathrm{JKF} 1 & =\frac{1}{b} \sum_{i=1}^{a} y_{i .}^{2}-\frac{y_{. .}^{2}}{N} \ldots \ldots . . . \\
\mathrm{JKF} 2 & =\frac{1}{a} \sum_{i=1}^{b} y_{. \mathrm{j}}^{2}-\frac{y_{. .}^{2}}{N} \ldots \ldots . . \\
\mathrm{JKG} & =\mathrm{JKT}-\mathrm{JKF} 1-\mathrm{JKF} 2
\end{aligned}
$$

dimana:

$a \quad=$ banyak ulangan data observasi dari Faktor-1

$b \quad$ = banyak ulangan data observasi dari Faktor-2

$y_{i j}=$ data observasi ke- $i$ dan $j$ dengan $i=1,2, \ldots$, a dan $j=1,2, \ldots, \mathrm{b}$

$y_{i .}=$ total data observasi ke- $i$

$y_{. j}=$ total data observasi ke- $j$

$y_{. .}=$total keseluruhan data observasi

$N=$ total sampel

Jika $\mathrm{H}_{0}$ di tolak maka analisis dapat dilanjutkan ke perbandingan berganda untuk melihat level faktor yang memberikan efek secara signifikan terhadap respon dengan menggunakan metode Least Significant Difference (LSD) dengan Persamaan (6).

$$
L S D=t_{\alpha / 2}(N-a) \sqrt{\frac{2 J K G}{n}}
$$

Langkah-langkah analisis dalam studi ini adalah sebagai berikut:

1. Mendeskripsikan hasil perhitungan produktivitas dan pertumbuhannya

2. Menguji efek perbedaan provinsi dan tahun terhadap produktivitas dan pertumbuhannya dengan metode ANAVA Dua Arah.

3. Mendeskripsikan PDRB dan angkatan kerja dari 3 provinsi dan dari tahun ke tahun

\begin{tabular}{|c|c|c|c|c|c|c|c|}
\hline \multirow{2}{*}{ Provinsi } & \multicolumn{6}{|c|}{ Tahun } & \multirow{2}{*}{ Rata-rata } \\
\hline & 2013 & 2014 & 2015 & 2016 & 2017 & 2018 & \\
\hline Bali & 0.147 & 0.171 & 0.192 & 0.213 & 0.233 & 0.254 & 0.170 \\
\hline Jawa Timur & 1.193 & 1.263 & $1.331 *$ & 1.406 & 1.482 & 1.564 & 1.373 \\
\hline Jawa Tengah & 0.824 & 0.861 & 0.909 & 0.954 & 1.000 & 1.050 & 0.933 \\
\hline
\end{tabular}

4. Menguji efek perbedaan provinsi dan tahun terhadap PDRB dan angkatan kerja metode ANAVA Dua Arah.

\section{HASIL DAN PEMBAHASAN}

Tabel 2. PDRB di tiga provinsi selama enam tahun terakhir (milyar rupiah).

* Data hasil estimasi karena data tidak tersedia Sumber: BPS Provinsi Bali, Jawa Timur, dan Jawa Tengah

Tabel 3. Pekerja di tiga provinsi selama enam tahun terakhir (juta jiwa).

\begin{tabular}{lccccccc}
\hline \multirow{2}{*}{ Provinsi } & \multicolumn{7}{c}{ Tahun } \\
\cline { 2 - 7 } & 2013 & 2014 & 2015 & 2016 & 2017 & 2018 & Rata-rata \\
\hline Bali & 2.15 & 2.18 & 2.37 & 2.32 & 2.29 & 2.37 & 2.28 \\
Jawa Timur & 19.21 & 18.94 & 19.06 & 18.76 & 19.68 & 20.02 & 19.28 \\
Jawa Tengah & 16.47 & 16.55 & 16.44 & 16.44 & 16.49 & 16.49 & 16.48 \\
\hline
\end{tabular}

Sumber: BPS Provinsi Bali, Jawa Timur, dan Jawa Tengah 
Tabel 2 dan Tabel $\mathbf{3}$ serta Gambar 1 dan Gambar $\mathbf{2}$ berturut turut menampilkan data PDRB dan jumlah pekerja di tiga provinsi yaitu Provinsi Bali, Jawa Timur, dan Jawa Tengah yang diperoleh dari data BPS secara online (BPS Bali, 2019) (BPS Jawa Timur, 2019) (BPS Jawa Tengah, 2019). PDRB Jawa Timur pada tahun 2015 tidak tersedia di website BPS Jawa Timur, sehingga produktivitas pada tahun 2015 diestimasi menggunakan rata-rata tahun sebelum dan sesudahnya. Selain itu, data pekerja yang tersedia di website BPS Provinsi Bali dan Jawa Timur adalah angkatan kerja, sedangkan pengukuran produktivitas regional diukur berdasarkan rasio PDRB dan jumlah tenaga kerja aktif. Angkatan kerja merupakan gabungan jumlah tenaga kerja aktif dan jumlah pengangguran. Dengan asumsi tingkat pengangguran di Bali dan Jawa Timur sama dengan di Jawa Tengah yaitu sekitar 6\% maka jumlah tenaga kerja aktif di Jawa Timur dan Bali dihitung dengan cara menjumlahkan angkatan kerja dikurangi $6 \%$ dari angkatan Kerja.

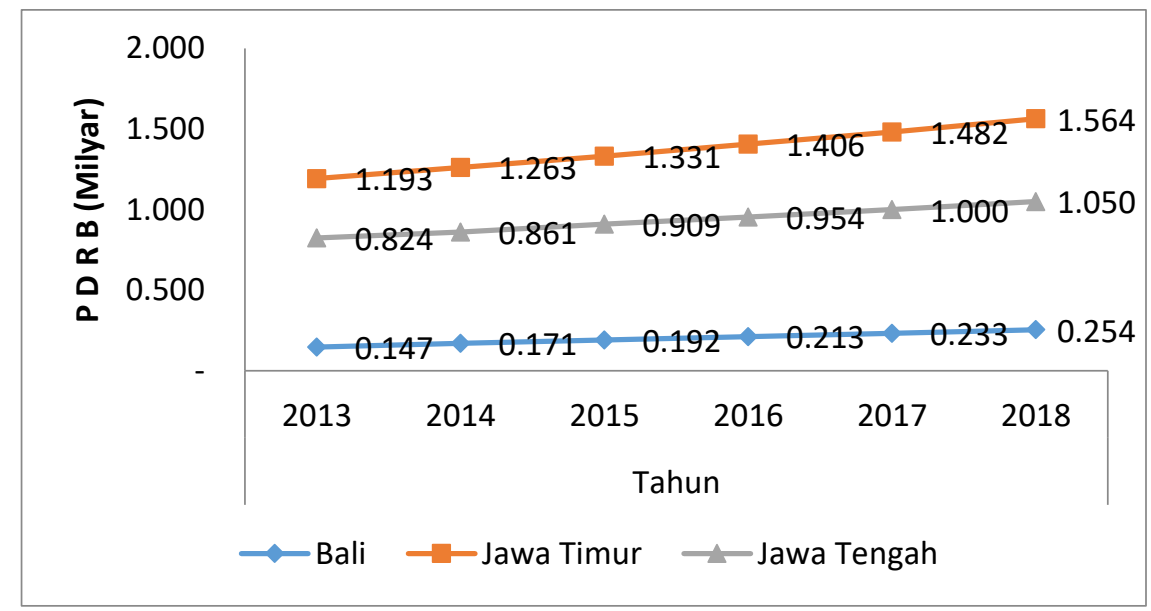

Gambar 1. PDRB di tiga provinsi dalam enam tahun terakhir.

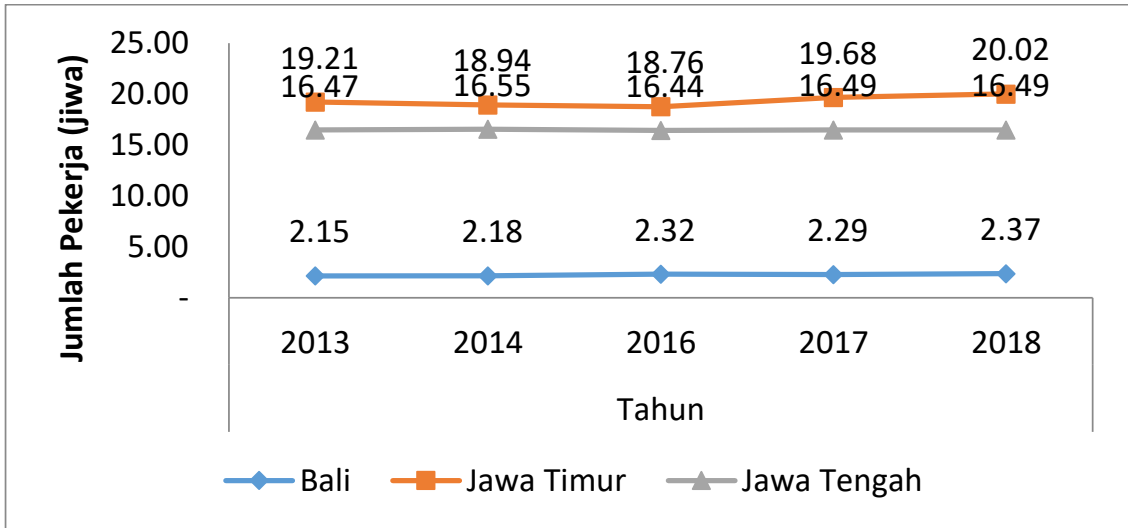

Gambar 2. Jumlah pekerja di tiga provinsi dalam enam tahun terakhir.

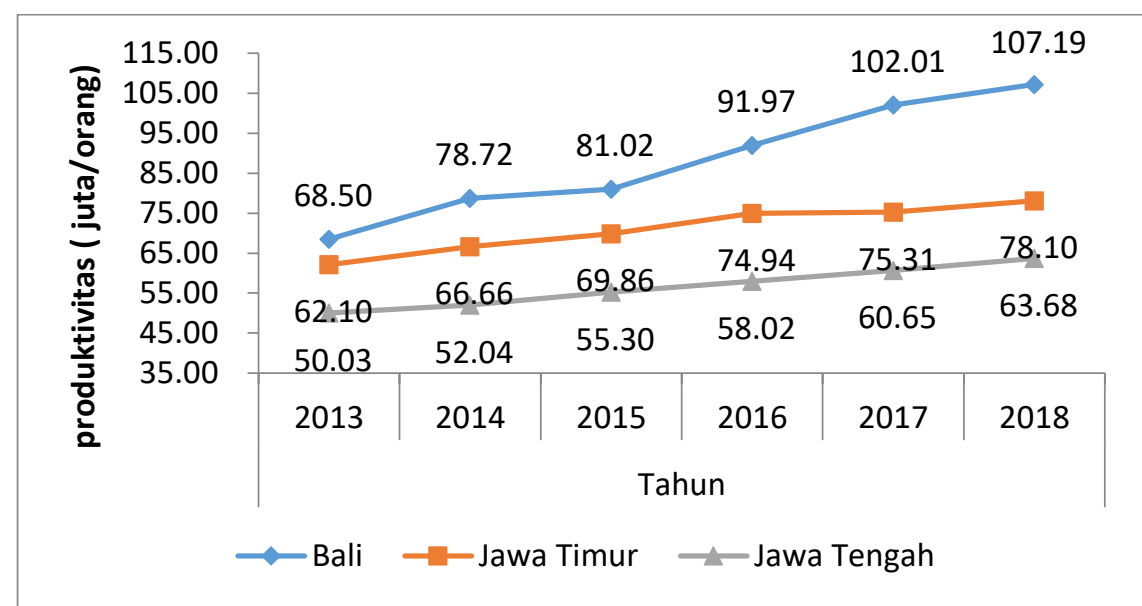

Gambar 3. Produktivitas di tiga provinsi dalam enam tahun terakhir. 
Tabel 4. Produktivitas di tiga provinsi selama enam tahun terakhir.

\begin{tabular}{lccccccc}
\hline \multirow{2}{*}{ Provinsi } & \multicolumn{6}{c}{ Tahun } & \multirow{2}{*}{ Rata-rata } \\
\cline { 2 - 7 } & 2013 & 2014 & 2015 & 2016 & 2017 & 2018 & \\
\hline Bali & 68.50 & 78.72 & 81.02 & 91.97 & 102.01 & 107.19 & 88.24 \\
Jawa Timur & 62.10 & 66.66 & $69.86^{*}$ & 74.94 & 75.31 & 78.10 & 71.42 \\
Jawa Tengah & 50.03 & 52.04 & 55.30 & 58.02 & 60.65 & 63.68 & 56.62 \\
\hline
\end{tabular}

Dengan menggunakan persamaan (1) dan data pada Tabel 2 dan Tabel 3, produktivitas di tiga provinsi dapat dihitung dan disajikan pada Tabel 4 dan Gambar 3. Berdasarkan Tabel 4, dapat di lihat bahwa dalam enam tahun terakhir rata-rata produktivitas pekerja paling tinggi terletak di Provinsi Bali dengan rata-rata produktivitas 88 juta rupiah per orang; artinya setiap pekerja memberikan kontribusi sebesar 88 juta rupiah per tahun. Rata-rata produktivitas di Provinsi Bali selama enam tahun terakhir 1.2 kali lebih besar dari produktivitas Provinsi Jawa Timur dan 1.5 kali dari produktivitas Provinsi Jawa Tengah. Menurut Purba, dkk. produktivitas pekerja di Indonesia pada tahun 2015 mencapai 78.18 juta rupiah per orang (Purba, Hasan, Marhaeni, \& Rustam, 2016). Nilai ini sudah dicapai Provinsi Bali pada tahun 2014. Selain itu, nilai produktivitas di Bali sudah lebih tinggi dari hasil perhitungan Sakernas 2017 yang menyatakan produktivitas Bali baru mencapai 60.44 juta rupiah per pekerja (Maya, 2019).

Perbedaan Provinsi dan tahun terhadap produktivitas pekerja kemudian diuji menggunakan ANAVA Dua Arah dengan $a=5 \%$. Hipotesis yang akan diuji adalah sebagai berikut:

1. $\mathrm{H}_{0}: \mathrm{T}_{1}=\mathrm{T}_{2} \ldots \ldots=\mathrm{T}_{\mathrm{i}}=0$ (tidak ada efek perbedaan provinsi terhadap produktivitas)

$H_{1}$ : paling sedikit ada satu $T_{i} \neq 0$

2. $H_{0}: \beta_{1}=\beta_{2} \ldots \ldots=\beta_{j}=0$ (tidak ada efek perbedaan tahun terhadap produktivitas)

$\mathrm{H}_{1}$ : paling sedikit ada satu $\beta_{\mathrm{j}} \neq 0$

Hasil pada Tabel $\mathbf{5}$ menunjukkan bahwa produktivitas pekerja tidak sama untuk semua provinsi maupun tahun.

Tabel 5. Tabel ANAVA Dua Arah provinsi dan tahun terhadap produktivitas

\begin{tabular}{lcccccc}
\hline Sumber variasi & $\mathrm{JK}$ & $\mathrm{db}$ & $\mathrm{JRK}$ & $F_{\mathrm{h}}$ & $p$-value & $F$ \\
\hline Provinsi & 3005.08 & 2 & 1502.54 & 50.24 & 0.00001 & 4.10 \\
Tahun & 1114.10 & 5 & 222.82 & 7.45 & 0.00372 & 3.33 \\
Galat & 299.05 & 10 & 29.90 & & & \\
Total & 4418.23 & 17 & & & & \\
\hline
\end{tabular}

Tabel 6. Selisih rata-rata produktivitas antar provinsi beserta nilai LSDnya.

\begin{tabular}{lcccc}
\hline \multicolumn{1}{c}{ Provinsi } & Rata-Rata & Bali & Jawa Timur & Jawa Tengah \\
\hline Bali & 88.24 & 0.00 & & \\
Jawa Timur & 71.16 & 17.08 & 0.00 & 0.00 \\
Jawa Tengah & 56.62 & 31.62 & 14.54 & 0.313 \\
\hline \multicolumn{5}{c}{ LSD $=10.323 ; \mathrm{t}_{0.025 ; 15}=2.313$} \\
\hline
\end{tabular}

Tabel 7. Selisih rata-rata produktivitas antar tahun dan nilai LSD-nya.

\begin{tabular}{ccrrrrrr}
\hline Tahun & Rata-rata & \multicolumn{1}{c}{2013} & 2014 & 2015 & 2016 & 2017 & 2018 \\
\hline 2013 & 60.21 & 0.00 & & & & & \\
2014 & 65.81 & 5.60 & 0.00 & & & & \\
2015 & 68.73 & 8.52 & 2.92 & 0.00 & & & \\
2016 & 74.98 & 14.77 & 9.17 & 6.25 & 0.00 & & \\
2017 & 79.33 & 19.12 & 13.52 & 10.60 & 4.35 & 0.00 & \\
2018 & 82.99 & 22.78 & 17.18 & 14.26 & 8.01 & 3.66 & 0.00 \\
\hline \multicolumn{7}{c}{ LSD $=6.879 ; \mathrm{t}_{0.025 ; 12=2.179}$} \\
\hline
\end{tabular}


Hasil uji perbandingan berganda menggunakan metode LSD untuk menentukan provinsi dan tahun mana yang produktivitas pekerjanya berbeda berturut-turut diberikan oleh Tabel $\mathbf{6}$ dan Tabel 7. Berdasarkan Tabel 6, semua selisih rata-rata melebihi nilai LSD yang menunjukkan adanya perbedaan produktivitas yang signifikan antar provinsi. Sementara hasil uji pada Tabel 7 menunjukkan bahwa terdapat perbedaan siginifikan antar produktivitas yang memiliki selisih dua tahun atau lebih, sedangkan selisih perbedaan produktivitas dari tahun ke tahun tidak signifikan.

Tabel menunjukkan pertumbuhan produktivitas pekerja dari tahun ke tahun selama enam tahun. Rata-rata pertumbuhan di Provinsi Bali adalah 9.5\% sedangkan di Provinsi Jawa Timur dan Jawa tengah hanya mencapai $4.7 \%$ dan $4.9 \%$. Tabel menunjukkan pertumbuhan antara provinsi berbeda secara signifikan pada level signifan $11 \% \mathrm{Hal}$ ini dipertegas melalui hasil uji perbandingan berganda pada Tabel yang menunjukkan bahwa terdapat selisih pertumbuhan produktivitas antara Bali dan Jawa Tengah serta Bali dan Jawa Timur. Sementara itu, tidak terdapat perbedaan pertumbuhan produktivitas antara Jawa Tengah dan Jawa Timur karena nilai selisihnya kurang dari nilai LSD.

Tabel 8. Pertumbuhan produktivitas dari tahun ke tahun di tiga provinsi.

\begin{tabular}{lrrrrrr}
\hline \multirow{2}{*}{ Provinsi } & \multicolumn{5}{c}{ Tahun } & \multirow{2}{*}{ Rata-Rata } \\
\cline { 2 - 6 } & 2014 & 2015 & 2016 & 2017 & 2018 & \\
\hline Bali & $15 \%$ & $3 \%$ & $14 \%$ & $11 \%$ & $5 \%$ & $9.5 \%$ \\
Jawa Timur & $7 \%$ & $5 \%$ & $7 \%$ & $1 \%$ & $4 \%$ & $4.7 \%$ \\
Jawa Tengah & $4 \%$ & $6 \%$ & $5 \%$ & $5 \%$ & $5 \%$ & $4.9 \%$ \\
\hline
\end{tabular}

Tabel 9. ANAVA dari pertumbuhan produktivitas antar provinsi dari tahun ke tahun.

\begin{tabular}{lcccccc}
\hline Sumber Variasi & $\mathrm{JK}$ & $\mathrm{db}$ & $\mathrm{RJK}$ & $F_{\mathrm{h}}$ & $p$-value & $F$ \\
\hline Provinsi & 0.01 & 2 & 0.004 & 3.11 & 0.10 & 3.11 \\
Tahun & 0.01 & 4 & 0.001 & 1.15 & 0.40 & 1.15 \\
Error & 0.01 & 8 & 0.001 & & & \\
\hline Total & 0.02 & 14 & & & & \\
\hline
\end{tabular}

Tabel 10. Selisih rata-rata pertumbuhan produktivitas antar provinsi beserta nilai LSD-nya.

\begin{tabular}{lcccc}
\hline \multicolumn{1}{c}{ Provinsi } & Rata-rata & Bali & Jawa Timur & Jawa Tengah \\
\hline Bali & 0.095 & 0.000 & \\
Jawa Timur & 0.047 & 0.048 & 0.000 & \\
Jawa Tengah & 0.049 & 0.046 & 0.002 & 0.000 \\
\hline \multicolumn{5}{c}{ LSD $=0.035 ; \mathrm{t}_{0.025 ; 12}=1.762$} \\
\hline
\end{tabular}

Berdasarkan data BPS dari masing-masing provinsi, diketahui bahwa Provinsi Bali memiliki ratarata pertumbuhan produktivitas pekerja tertinggi sebesar $28 \%$ yang terletak di sektor Ketenagalistrikan dan Pengadaan Gas dan Listrik. Sektor yang meningkat sebesar $20 \%$ adalah sektor Penyediaan Akomodasi, sedangkan Sektor Transportasi dan Pergudangan rata-rata meningkat 19\%. Sementara itu, sektor yang rata-rata pertumbuhan produktivitas pekerjanya mencapai $18 \%$ adalah sektor Pergudangan dan Jasa Penunjang, Jasa Pendidikan dan Jasa Kesehatan serta Kegiatan Sosial. Sektor Penyedia Makanan dan Minuman mencapai rata-rata pertumbuhan $16 \%$. Tidak ada sektor yang mengalami penurunan produktivitas di Provinsi Bali dalam enam tahun terakhir.

Di sisi lain, rata-rata pertumbuhan produktivitas di Jawa Tengah selama enam tahun terakhir mencapai 32\% yaitu pada sektor Pertambangan Minyak, Gas, dan Panas Bumi. Sektor yang tumbuh sebesar $19 \%$ adalah sektor Angkutan Rel, sementara sektor Pergudangan dan Jasa Penunjang Angkutan; Pos dan Kurir, sektor Komunikasi dan Informasi serta sektor Asuransi dan Dana Pension tumbuh sekitar $10 \%$ sampai $11 \%$. Sektor yang mengalami penurunan produktivitas di provinsi ini adalah sektor Kehutanan dan Penebangan Kayu, sektor Industri Barang Logam, sektor Komputer, Barang Elektronik, Optik, dan sektor Peralatan Listrik.

Di Provinsi Jawa Timur, rata-rata peningkatan produktivitas tertinggi selama enam tahun diraih oleh sektor Makanan dan Minuman yang mencapai 10\%; diikuti oleh sektor Angkutan Rel dan 
Angkutan Darat yang mencapai rata-rata pertumbuhan $8 \%$. Sementara sektor Penyedia Jasa Akomodasi memiliki rata-rata pertumbuhan sebesar $9 \%$.

\section{KESIMPULAN}

Rata-rata produktivitas paling tinggi berada di Provinsi Bali yang mencapai $88 \%$ dalam enam tahun terakhir. Hal ini disebabkan rata-rata pertumbuhan produktivitas dari tahun ke tahun mencapai $9.5 \%$ serta didukung rata-rata pertumbuhan per sektor yang paling tinggi mencapai $16 \%$ sampai $28 \%$. Rata-rata pertumbuhan ini melebihi rata-rata pertumbuhan paling tinggi per sektor di Jawa Timur yang hanya mencapai $10 \%$.

\section{UCAPAN TERIMAKASIH}

Penulis mengucapkan terima kasih kepada Badan Pusat Statistik, khususnya BPS Bali, BPS Jawa Timur dan BPS Jawa Tengah yang telah menyediakan data dari tahun ke tahun sehingga mempermudah dalam melakukan eksplorasi dan penelitian. Kamu juga berterimakasih kepada semua pihak yang telah membantu sehingga data mudah diperoleh dan di analisis.

\section{DAFTAR PUSTAKA}

BPS Bali. (2019, Juli 15). Badan Pusat Statistik Bali. Diambil kembali dari Badan Pusat Statistik Bali: https://bali.bps.go.id/subject/6/tenaga-kerja.html\#subjekViewTab3

BPS Bali. (2019, Juli 15). Badan Pusat Statistik Bali. Diambil kembali dari Badan Pusat Statistik Bali: httpbali.bps.go.id/subject/52/produk-domestik-regional-bruto--lapangan-usaha-.html\#subjekViewTab3

BPS Jawa Tengah. (2019, Juli 15). Badan Pusat Statistik Jawa Tengah. Diambil kembali dari Badan Pusat Statistik Jawa Tengah: https://jateng.bps.go.id/subject/6/tenaga-kerja.html\#subjekViewTab3

BPS Jawa Tengah. (2019, Juli 15). Badan Pusat Statistik Jawa Tengah. Diambil kembali dari Badan Pusat Statistik Jawa Tengah: https://jateng.bps.go.id/subject/52/produk-domestik-regional-bruto--lapanganusaha-.html\#subjekViewTab3

BPS Jawa Timur. (2019, Juli 15). Badan Pusat Statistik Jawa Timur. Diambil kembali dari Badan Pusat Statistik Jawa Timur: https://jatim.bps.go.id/subject/6/tenaga-kerja.html\#subjekViewTab3

BPS Jawa Timur. (2019, Juli 15). Badan Pusat Statistik Jawa Timur. Diambil kembali dari Badan Pusat Statistik Jawa Timur: https://jatim.bps.go.id/subject/52/produk-domestik-regionalbruto.html\#subjekViewTab3

Heizer, J., \& Render, B. (2014). Operation Management (11th ed.). New York: Pearson.

Maya, C. (2019, Mei). Bali Post. Diambil kembali dari Bali Post: https://www.balipost.com/ekonomi

Montgomery, D. C. (2001). Design and Analysis of Experiments (5th ed.). New York: John Wiley \& Sons Inc.

Purba, S., Hasan, I., Marhaeni, H., \& Rustam. (2016). Pengukuran Produktivitas Nasional, Regional, dan Sektoral. Jakarta: Badan Pusat Statistika dan Kementrian Ketenagakerjaan Republik Indonesia.

Tefi, M. (2004). Tingkat Upah dan Produktivitas Tenaga Kerja Provinsi DKI Jakarta Tahun 2016. Bogor: Pasca Sarjana IPB. 